\title{
YOLK SAC TUMOUR IN A PREMENARCHAL GIRL: A CASE REPORT
}

\author{
Sourav Das ${ }^{1}$, Avishek Bhadra², Pallab Kumar Mistri³ ${ }^{3}$ Bandana Biswas ${ }^{4}$, Mrinmoyee Dutta ${ }^{5}$
}

\section{HOW TO CITE THIS ARTICLE:}

Sourav Das, Avishek Bhadra, Pallab Kumar Mistri, Bandana Biswas, Mrinmoyee Dutta. "YOLK SAC Tumour in a Premenarchal Girl: A Case Report". Journal of Evolution of Medical and Dental Sciences 2015; Vol. 4, Issue 24, March 23; Page: 4232-4234, DOI: 10.14260/jemds/2015/611

ABSTRACT: Yolk sac tumour, otherwise known as endodermal sinus tumour, is a rare and highly malignant germ cell tumour accounting for approximately $10 \%$ of malignant germ cell tumours. The tumour usually presents as a rapidly growing mass in young women. Here we present a case of a young premenarchal girl with a huge ovarian tumour which proved to be a yolk sac tumour and was successfully managed.

KEYWORDS: Yolk sac tumour, Endodermal sinus tumour, Premenarchal.

INTRODUCTION: Ovarian yolk sac tumour is a subtype of germ cell tumour, characterized histologically by papillary projections, which resembles the yolk sac of the rodent placenta. This is a rare tumour; but it accounts for about $10 \%$ of malignant germ cell tumours. The tumour usually presents as a rapidly growing mass in young women.

CASE REPORT: Ms. MD, a 13 years old premenarchal girl presented with dull aching pain in the lower abdomen for the last 3 months along with a gradually increasing generalised swelling of the abdomen. On examination, she had mild pallor and her nutrition was poor. Her BMI was $18.22 \mathrm{~kg} / \mathrm{m}^{2}$. On abdominal examination a tense cystic lump was palpable extending upto the xiphisternum whose lower pole could not be reached suggesting the lump to be arising from the pelvis. No ascitis could be delineated. The mass was non tender with restricted mobility due to its huge size. It was more or less smooth with regular margins.

USG showed a very large heterogeneously echoic SOL in the lower abdomen extending upto the upper abdomen below xiphoid. Outline of uterus was poorly visualised. Ovaries could not be delineated. Small ascitis was noted. Laboratory investigations for tumour markers of ovarian tumour were done and depicted in Table 1.

\begin{tabular}{|c|c|c|}
\hline TUMOUR MARKERS & VALUE & NORMAL \\
\hline CA-125 & $366.2 \mathrm{U} / \mathrm{ml}$ & $<35 \mathrm{U} / \mathrm{ml}$ \\
\hline$\beta$-HCG & $<0.10 \mathrm{mIU} / \mathrm{ml}$ & $<5.0 \mathrm{mIU} / \mathrm{ml}$ \\
\hline AFP & $17,965 \mathrm{ngm} / \mathrm{ml}$ & $<50 \mathrm{ngm} / \mathrm{ml}$ \\
\hline $\mathrm{LDH}$ & $338 \mathrm{U} / \mathrm{L}$ & $<250 \mathrm{U} / \mathrm{L}$ \\
\hline \multicolumn{3}{|c|}{ Table 1: Blood values of tumour markers investigated: }
\end{tabular}

HCG: Human Chorionic Gonadotrophin; AFP: Alpha Feto Protein; LDH: Lactate Dehydrogenase

An elective exploratory laparotomy was done after all preoperative investigations. On opening the abdomen by right paramedian incision, minimal amount of ascitic fluid was drained and also collected for cytological investigation. 
A big rounded solid cystic mass of around $12 \mathrm{~cm} \times 10 \mathrm{~cm}$ size noted arising from right ovary. Left ovary, bilateral tubes were healthy and uterus was of normal size. The mass was adhered to the small intestine with a band like structure. The mass was delivered through the incision line and right sided oophorectomy was done. The band like peritoneal adhesion with intestine was clamped, cut and transfixed with absorbable suture. All abdominal organs inspected and palpated for evidences of metastasis and peritoneal biopsy taken. After peritoneal toileting with normal saline and putting an abdominal drain, abdomen was closed in layers. Specimen was sent for Histopathological Examination.

The postoperative period was uneventful. 2 units of whole blood transfusion were given. Drain output was about $100 \mathrm{ml}$ of serous fluid in the first 2 days, which gradually decreased and drain omitted on the 4 th postoperative day. Stitches were removed on the 10 th postoperative day.

The histopathology of the specimen showed presence of cystic spaces lined by flattened epithelium. The cystic spaces sometimes contained tuft of vascular tissues suggesting Schiller-Duval bodies. This histological picture is suggestive of endodermal sinus tumour or yolk sac tumour of the ovary. Ascitic fluid cytology was negative for malignant cells.

DISCUSSION: Yolk sac tumour, so called endodermal sinus tumour, is a rare and highly malignant germ cell tumour ${ }^{1}$ and accounts for about $10 \%$ of malignant germ cell tumours. The tumour usually presents as a rapidly growing mass in young women. ${ }^{2}$ Clinically the tumour presents as an ovarian, pelvic, retroperitoneal or a sacrococcygeal mass. Current evidence has proved Teilum's postulate that yolk sac tumour is a unilaterally developed teratoma mimicking embryonal yolk sac tissue. ${ }^{3}$

Germ cell tumours constitute approximately $20 \%$ of all ovarian neoplasms. Most of them are seen in children and young adults. Approximately $95 \%$ of these tumours are benign cystic teratomas; the young the patient more likely the germ cell tumour will be malignant. ${ }^{4}$ Almost always a unilateral solid or partly solid and cystic tumour, displays a wide range of histologic patterns like microcystic, endodermal sinus, solid, alveolar-glandular, papillary, myxomatous, macrocystic, hepatoid, primitive endodermal or polyvesicular vitelline. Classic pattern shows perivascular formations (Schiller-Duval bodies) and eosinophilic globules that contain AFP5. Differential diagnosis of yolk sac tumour includes embryonal carcinoma and other germ cell tumours such as seminoma and dysgerminoma.

\section{REFERENCES:}

1. Turkish journal of cancer, summary, yolk sac tumour, a clinical and therapeutical analysis of 9 cases. 1991, volume 21, number 2, page(s) 76-82.

2. Pettersson H, Baert A, Hricak H, Coakley F, editors. The Encyclopaedia of Medical Imaging: Gastrointestinal and Urogenital Imaging, Volume 4; 1999.

3. Afroz N, Khan N, Chana RS. Cytodiagnosis of yolk sac tumour. Indian J Pediatr 2004; 71: 939942 [Gonzalez-Crussi F. The human yolk sac and yolk sac (Endodermal sinus) tumours, a review. Perspect Ped. Path. 1979; 5: 179].

4. Rosai and Ackerman's surgical pathology, Volume 2, chapter 19; 1681.

5. Siltanen S, Anttonen M, Heikkilä P, Narita N, Laitinen M, Ritvos O, Wilson D, HeikinheimoM. Transcription Factor GATA-4 Is Expressed in Pediatric Yolk Sac Tumors. Am J Pathol. 1999 Dec; 155(6):1823-29. 


\section{AUTHORS:}

1. Sourav Das

2. Avishek Bhadra

3. Pallab Kumar Mistri

4. Bandana Biswas

5. Mrinmoyee Dutta

\section{PARTICULARS OF CONTRIBUTORS:}

1. Senior Resident, Department of Obstetrics \& Gynaecology, ESIC Medical College, Joka, Kolkata.

2. Assistant Professor, Department of Obstetrics \& Gynaecology, Medical College, Kolkata.

3. Associate Professor, Department of Obstetrics \& Gynaecology, Medical College, Kolkata.

FINANCIAL OR OTHER COMPETING INTERESTS: None
4. Professor, Department of Obstetrics \& Gynaecology, Medical College, Kolkata.

5. Junior Resident, Department of Obstetrics \& Gynaecology, Medical College, Kolkata.

\section{NAME ADDRESS EMAIL ID OF THE CORRESPONDING AUTHOR:}

Avishek Bhadra, \# C-13, Sourav Abasan, ED Block, Sector II,

Salt Lake, Kolkata-700091, West Bengal.

E-mail: drabhadra@gmail.com

Date of Submission: 05/02/2015.

Date of Peer Review: 06/02/2015.

Date of Acceptance: 10/03/2015.

Date of Publishing: 23/03/2015. 